\title{
The Association between Heart Rate Variability and Cognitive Impairment in Middle-Aged Men and Women
}

\author{
The Whitehall II Cohort Study
}

\author{
Annie Britton $^{a} \quad$ Archana Singh-Manoux $^{a, c}$ Katerina Hnatkova ${ }^{b}$ Marek Malik $^{b}$ \\ Michael G. Marmot ${ }^{a}$ Martin Shipley ${ }^{a}$ \\ ${ }^{a}$ Department of Epidemiology and Public Health, University College London, and ${ }^{\mathrm{b}}$ Cardiac and Vascular Sciences, \\ St George's University of London, London, UK; ' INSERM U687-IFR69, Hôpital Paul Brousse, Villejuif, France
}

\author{
Key Words \\ Autonomic function $\cdot$ Cognitive impairment $\cdot$ Heart rate \\ variability $\cdot$ Cohort studies
}

Further studies are needed to verify the potential role of HRV measures in predicting the degeneration of cognitive function at older ages.

Copyright $\odot 2008$ S. Karger AG, Basel

\begin{abstract}
Background: To examine the relationship between reduced heart rate variability (HRV) and cognitive function in middleaged adults in the general population. Methods: HRV, in both time and frequency domains, and cognitive functioning were measured twice in 5,375 male and female participants of the UK Whitehall II study (mean ages $=55$ and 61 years, respectively). Logistic regression was used to model associations between HRV and cognition [short-term verbal memory, reasoning (Alice Heim 4-I), vocabulary, phonemic and semantic fluency]. Cross-sectional associations were assessed at both waves, and longitudinal associations were measured as changes in cognition over the 5-year follow-up. Results: No consistent associations were found in men or women, either in the cross-sectional, prospective or the longitudinal analyses of declines in cognition. Conclusion: Reduced cardiovascular autonomic function does not contribute to cognitive impairment in this middle-aged population.
\end{abstract}

\section{Introduction}

Increases in life expectancy make cognitive function an important health outcome. Poor cognitive functioning among adults is not only linked to dementia $[1,2]$ and mortality [3-5], but has also been shown to be associated with some degree of functional impairment [6]. It is important, therefore, to explore the possible predictors of cognitive impairment in order to better target the preventive strategies and public health messages.

All authors designed the study, were involved in data acquisition and prepared the text. A.B. wrote the first draft. M.S. was primarily responsible for statistical analyses. M.M. was responsible for quality assurance and control.

\begin{tabular}{ll}
\hline KARGER & ( 2008 S. Karger AG, Basel \\
0251-5350/08/0312-0115\$24.50/0 \\
$\begin{array}{l}\text { Fax +41 61 306 1234 } \\
\begin{array}{l}\text { E-Mail karger@karger.ch } \\
\text { www.karger.com }\end{array}\end{array}$ & $\begin{array}{l}\text { Accessible online at: } \\
\text { www.karger.com/ned }\end{array}$
\end{tabular}

Annie Britton

Department of Epidemiology and Public Health

University College London, 1-19 Torrington Place

London WC1E 6BT (UK)

Tel. +44 207679 5626, Fax +44 207813 0242, E-Mail a.britton@ucl.ac.uk 
Existing research reveals that there are multiple determinants of cognitive decline. Besides age, other factors widely implicated in cognitive decline are pathology, socio-economic factors [7], vascular disease and risk factors (such as hypertension, diabetes mellitus, cholesterol levels, fibrinogen levels) [8-10] and lifestyle behavioural factors $[11,12]$. The association between cardiovascular autonomic function and cognitive function is less well explored, although there are several plausible pathways through which the two may be linked, for example via coronary heart disease $[13,14]$, vascular disease, hypertension [15], immune dysfunction/inflammation [16] and others [17].

Heart rate variability (HRV) is a non-invasive measure of autonomic input to the heart rate, which has successfully been used to estimate the modulation of autonomic tone. HRV is determined by the interaction of cardiac sympathetic and parasympathetic activity, which causes changes in the beat-to-beat intervals and changes in the frequency components of the heart rate. Short-term variations in the beat-to-beat interval (measured as the standard deviation in normal-to-normal intervals; SDNN) are reduced by decreased parasympathetic activity or sympathetic over stimulation. Low-frequency $(\mathrm{LF})$ power (typically $0.04-0.15 \mathrm{~Hz}$ ) reflects a combination of both parasympathetic and sympathetic heart rate modulations. Low HRV predicts coronary disease incidence [18], worse prognosis [19-21], and is linked to risk factors for cognitive impairment, such as high cholesterol, raised blood pressure and raised cortisol [17, 22, 23].

To date, there has been very little research as to whether or not low HRV is associated with cognitive impairments or dementia, and the findings were mixed [24, 25]. The aim of this study, therefore, is to explore the association between reduced HRV and poor cognitive functioning among middle-aged men and women in a general population setting. We examined the cross-sectional, prospective and longitudinal associations by investigating the association between changes in HRV with changes in cognitive decline over a 5 -year period.

\section{Methods}

The Whitehall II study was established in 1985 as a longitudinal population-based study to examine the socio-economic gradient in health and disease among 10,308 civil servants, then aged $35-55$ years $[26,27]$. At the fifth and seventh phases of data collection (1997-1999 and 2002-2004, respectively) all study participants known to be alive and in the country were invited to a screening clinic. Completed cognitive function tests were avail-
Table 1. Characteristics of participants

\begin{tabular}{|c|c|c|c|c|}
\hline & \multicolumn{2}{|c|}{ Phase 5 (1997-1999) } & \multicolumn{2}{|c|}{ Phase 7 (2002-2004) } \\
\hline & men & women & men & women \\
\hline $\mathrm{n}$ & 3,248 & 1,255 & 3,190 & 1,201 \\
\hline Age, years & $55.5 \pm 6.0$ & $55.8 \pm 6.0$ & $60.9 \pm 5.9$ & $61.0 \pm 6.0$ \\
\hline \multicolumn{5}{|c|}{ Heart rate variability ${ }^{1}$} \\
\hline SDNN & $34.3 \pm 0.44$ & $32.5 \pm 0.44$ & $33.7 \pm 0.49$ & $34.5 \pm 0.47$ \\
\hline LF & $326.7 \pm 0.99$ & $243.9 \pm 0.96$ & $290.2 \pm 1.07$ & $270.3 \pm 1.04$ \\
\hline $\mathrm{HF}$ & $117.0 \pm 1.12$ & $141.5 \pm 1.15$ & $107.8 \pm 1.25$ & $146.3 \pm 1.17$ \\
\hline \multicolumn{5}{|c|}{ Cognitive functioning } \\
\hline Memory & $6.9 \pm 2.3$ & $7.0 \pm 2.7$ & $6.8 \pm 2.3$ & $7.0 \pm 2.7$ \\
\hline AH4-I & $49.0 \pm 9.7$ & $42.4 \pm 11.8$ & $46.3 \pm 9.9$ & $40.2 \pm 11.8$ \\
\hline Mill Hill & $25.9 \pm 3.7$ & $23.4 \pm 5.4$ & $25.8 \pm 3.7$ & $23.8 \pm 5.3$ \\
\hline Phonemic & $17.1 \pm 4.2$ & $16.7 \pm 4.8$ & $16.0 \pm 4.0$ & $15.7 \pm 4.4$ \\
\hline Semantic & $16.7 \pm 4.0$ & $16.0 \pm 4.7$ & $16.0 \pm 3.7$ & $15.3 \pm 4.4$ \\
\hline
\end{tabular}

${ }^{1}$ For HRV measures, geometric means are presented with SD of the logged values.

able for 6,073 participants at phase 5 ( $93 \%$ of those attending) and 6,370 at phase 7 (98\% of those attending). Because of the lack of availability of clinic staff, HRV recordings were not performed on all days during screening. HRV recordings were therefore available for 3,365 participants at phase 5 (51\% of those attending) and 4,095 at phase 7 (63\% of those attending), of whom 3,253 (97\%) at phase 5 and 4,033 (98\%) at phase 7 also had cognitive function measures available. A total of 5,375 participants $(3,809$ men and 1,566 women) had either cross-sectional or longitudinal data on HRV and cognitive function available, and this sample forms the basis of the analyses. The number of participants in each analysis varies according to data availability. The University College London ethics committee approved the study.

\section{Measures of HRV - Phases 5 and 7}

Five-minute supine resting 12-lead electrocardiograms were obtained using SEER MC recorders (GE Medical Systems, Milwaukee, Wisconsin, USA). The recorders were programmed to capture individual 10 -second electrocardiograms every $10 \mathrm{~s}$. Five minutes of beat-to-beat heart rate data were re-sampled at $500 \mathrm{~Hz}$ frequency in order to obtain a digitized sequence of R waves. HRV was analysed both in the time domain (SDNN) and in the frequency domain using the autoregressive method (BlackmanTukey algorithm). Frequency domain components were computed by integrating the power spectrum within 2 frequency bands: $0.04-0.15 \mathrm{~Hz}\left(\mathrm{LF}\right.$, in $\left.\mathrm{ms}^{2}\right)$ and $0.15-0.4 \mathrm{~Hz}\left(\mathrm{HF}\right.$, in $\left.\mathrm{ms}^{2}\right)$. All the calculations were performed using software written in-house.

Measures of Cognitive Function - Phases 5 and 7

Cognitive function was assessed with a battery of 5 standard tasks, chosen to provide a comprehensive evaluation of cognitive functioning in middle-aged adults. Cognitive tests were administered to each participant in the screening clinic using a tape recorder. The first test was a 20 -word free recall test of short-term verbal memory. Participants were presented a list of twenty 1- or 2 -syllable words at 2-second intervals, and were then asked to recall in writing as many of the words as possible (in any order) in 
Table 2. Cross-sectional associations between HRV (1 SD decrease) and cognitive functioning (odds of lowest quintile)

\begin{tabular}{|c|c|c|c|c|c|c|c|c|c|c|}
\hline & \multicolumn{2}{|c|}{ Memory } & \multicolumn{2}{|c|}{ AH4-I } & \multicolumn{2}{|c|}{ Mill Hill } & \multicolumn{2}{|c|}{ Phonemic } & \multicolumn{2}{|c|}{ Semantic } \\
\hline & OR & $95 \% \mathrm{CI}$ & OR & $95 \% \mathrm{CI}$ & OR & $95 \% \mathrm{CI}$ & OR & $95 \% \mathrm{CI}$ & OR & $95 \%$ CI \\
\hline \multicolumn{11}{|c|}{ HRV measures - phase $5^{1}$} \\
\hline SDNN & 1.08 & $0.97-1.20$ & 1.03 & $0.93-1.14$ & 1.03 & $0.94-1.14$ & 1.15 & $1.04-1.26$ & 1.07 & $0.97-1.18$ \\
\hline $\mathrm{HF}$ & 1.03 & $0.93-1.14$ & 1.00 & $0.91-1.11$ & 1.00 & $0.91-1.10$ & 1.09 & $0.99-1.20$ & 1.05 & $0.95-1.16$ \\
\hline $\mathrm{LF}$ & 1.14 & $1.02-1.26$ & 1.08 & $0.98-1.20$ & 1.10 & $1.00-1.21$ & 1.15 & $1.04-1.26$ & 1.11 & $1.01-1.23$ \\
\hline \multicolumn{11}{|c|}{ HRV measures - phase $7^{2}$} \\
\hline SDNN & 0.95 & $0.87-1.05$ & 0.93 & $0.85-1.02$ & 0.98 & $0.90-1.07$ & 1.00 & $0.92-1.10$ & 1.12 & $1.02-1.24$ \\
\hline $\mathrm{HF}$ & 0.94 & $0.86-1.03$ & 0.87 & $0.80-0.95$ & 0.97 & $0.89-1.06$ & 0.97 & $0.89-1.07$ & 1.04 & $0.94-1.14$ \\
\hline LF & 0.95 & $0.87-1.05$ & 0.95 & $0.87-1.05$ & 1.03 & $0.94-1.12$ & 1.01 & $0.92-1.10$ & 1.14 & $1.04-1.25$ \\
\hline
\end{tabular}

OR are adjusted for age, sex and highest educational attainment.

${ }^{1} \mathrm{n}=3,029$ (2,162 men, 847 women).

${ }^{2} \mathrm{n}=3,569$ (2,605 men, 964 women).

2 min [12]. The Alice-Heim 4-I (AH4-I) is composed of a series of 65 verbal and mathematical reasoning items of increasing difficulty [28]. It tests inductive reasoning, measuring the ability to identify patterns and infer principles and rules. Participants had 10 min to do this section. The Mill Hill Vocabulary Test is a test of verbal meaning and encompasses the ability to recognize and comprehend words [29]. We used the test in its multiple format, consisting of a list of 33 stimulus words, ordered by increasing difficulty, and 6 response choices. We used 2 measures of verbal fluency: phonemic and semantic [30]. Phonemic fluency was assessed via 'S' words and semantic fluency via 'animal' words. Subjects were asked to recall in writing as many words as possible beginning with ' $\mathrm{S}$ ' and as many animal names as they could. One minute was allowed for each test.

\section{Statistical Analyses}

SDNN, LF power and HF power were transformed by natural logarithms because their distributions were skewed. The association between a single standard deviation (SD) decrease in each HRV parameter and each cognitive function test was estimated using multiple logistic regression analyses. Poor cognitive function was indicated by being in the worst (sex-specific) quintile for each test.

We examined these relationships cross-sectionally at 2 time points (phase 5 and phase 7 ) and prospectively (phase $5 \mathrm{HRV}$ and phase 7 cognitive function). We also examined the association between HRV at phase 5 and cognitive decline over the 5 -year follow-up. These latter analyses were adjusted for the time interval between the 2 phases. Cognitive decline was defined as being in the worst quintile of change, and corresponded to a decrease of 2 or more words ( 3 or more for women) for memory, 8 or more points on the AH4-I, 2 or more words on the Mill Hill Vocabulary Test and 4 or more words on both the phonemic and semantic fluency measures. All analyses were carried out separately for men and women, but, as no gender differences were found, the combined results are presented. Adjustments were made for age, sex and highest educational attainment.

Heart Rate Variability and Cognitive Functioning
In sensitivity analyses, we explored whether HRV and cognitive function were associated in 2 sub-groups of participants: 1 group with hypertension (classified as systolic and diastolic blood pressure $>140 / 90 \mathrm{~mm} / \mathrm{Hg}$ or treatment for hypertension at phase 5 ), and 1 group with prevalent coronary heart disease (defined as angina or myocardial infarction at any previous phase).

\section{Results}

Characteristics of participants in these analyses are shown in table 1. Apart from memory, cognitive scores were equal or lower in women than in men, and in general the scores were lower at phase 7 . The cross-sectional associations, at phases 5 and 7 , between the HRV measures and the 5 cognitive tests are shown in table 2 . At phase 5, LF HRV was negatively associated with memory, the Mill Hill Vocabulary Test and phonemic and semantic fluency. For instance, a 1-SD decrease in LF was associated with greater odds of poor verbal memory [OR = 1.14 ; 95\% CI $=1.02-1.26]$. There was generally less evidence of an association between HRV and poor cognitive function at phase 7 .

Table 3 presents the prospective association between HRV at phase 5 and cognitive impairment at phase 7; there was little evidence of an association. The association between HRV at phase 5 and cognitive decline between phases 5 and 7 is shown in table 4 . There was some evidence to suggest that a lower HRV was associated with an increased likelihood of being in the worst quintile of change in the Mill Hill test. No other statistically significant associations were found. 
Table 3. Prospective association between HRV at phase 5 (1 SD decrease) and cognitive functioning at phase 7 (odds of lowest quintile)

\begin{tabular}{|c|c|c|c|c|c|c|c|c|c|c|}
\hline & \multicolumn{2}{|c|}{ Memory } & \multicolumn{2}{|c|}{ AH4-I } & \multicolumn{2}{|c|}{ Mill Hill } & \multicolumn{2}{|c|}{ Phonemic } & \multicolumn{2}{|c|}{ Semantic } \\
\hline & OR & $95 \% \mathrm{CI}$ & OR & $95 \% \mathrm{CI}$ & OR & $95 \%$ CI & OR & $95 \%$ CI & OR & $95 \%$ CI \\
\hline \multicolumn{11}{|c|}{ HRV measures } \\
\hline SDNN & 1.01 & $0.90-1.12$ & 1.03 & $0.93-1.15$ & 1.02 & $0.91-1.13$ & 1.10 & $0.99-1.22$ & 1.07 & $0.96-1.18$ \\
\hline $\mathrm{HF}$ & 0.98 & $0.88-1.10$ & 1.00 & $0.90-1.12$ & 1.01 & $0.91-1.13$ & 1.06 & $0.94-1.18$ & 1.00 & $0.90-1.12$ \\
\hline $\mathrm{LF}$ & 1.05 & $0.94-1.18$ & 1.05 & $0.94-1.18$ & 1.05 & $0.94-1.17$ & 1.09 & $0.98-1.22$ & 1.09 & $0.97-1.21$ \\
\hline
\end{tabular}

Total number of subjects $=2,669$ (1,937 men, 732 women). OR are adjusted for age, sex and highest educational attainment.

Table 4. Prospective association between HRV at phase 5 (1 SD decrease) and decline in cognitive functioning between phases 5 and 7 (odds of lowest quintile of change)

\begin{tabular}{|c|c|c|c|c|c|c|c|c|c|c|}
\hline & \multicolumn{2}{|c|}{ Memory } & \multicolumn{2}{|c|}{ AH4-I } & \multicolumn{2}{|c|}{ Mill Hill } & \multicolumn{2}{|c|}{ Phonemic } & \multicolumn{2}{|c|}{ Semantic } \\
\hline & OR & $95 \% \mathrm{CI}$ & OR & $95 \% \mathrm{CI}$ & OR & $95 \% \mathrm{CI}$ & OR & $95 \% \mathrm{CI}$ & OR & $95 \% \mathrm{CI}$ \\
\hline \multicolumn{11}{|c|}{ HRV measures } \\
\hline SDNN & 1.02 & $0.92-1.12$ & 1.05 & $0.95-1.17$ & 1.16 & $1.05-1.29$ & 0.97 & $0.88-1.07$ & 0.94 & $0.85-1.05$ \\
\hline $\mathrm{HF}$ & 1.01 & $0.91-1.11$ & 1.01 & $0.91-1.12$ & 1.18 & $1.06-1.31$ & 0.96 & $0.87-1.06$ & 0.90 & $0.81-1.00$ \\
\hline $\mathrm{LF}$ & 1.06 & $0.96-1.18$ & 1.04 & $0.93-1.15$ & 1.19 & $1.08-1.32$ & 0.98 & $0.88-1.08$ & 0.95 & $0.86-1.06$ \\
\hline
\end{tabular}

Total number of subjects $=2,595$ (1,883 men, 712 women). OR are adjusted for age, sex and highest educational attainment and the time interval between phases 5 and 7 .

We carried out further analysis in a sub-group of participants with hypertension, and there was no evidence of an association between HRV and cognition (data not shown). In the relatively small sub-group of participants with prevalent coronary heart disease, there was a suggestion that the effects were stronger (tables 5 and 6).

\section{Discussion}

This study of middle-aged adults suggests that low HRV is not consistently related to poor cognitive function. This finding supports an earlier case-control study, in which 39 individuals with mild cognitive impairment were found to have similar HRV to controls [25]. However, in a cross-sectional analysis of 311 older disabled women, Kim et al. [24] reported that cardiac autonomic dysfunction, particularly low HF power, was associated with 6.7 times greater odds of cognitive impairment. Our analysis is on a relatively healthy general population sample, and there appears to be little evidence of an association between HRV and cognition in middle age.

Dementia occurs late in life, but it is increasingly recognized that there is a long preclinical phase characterized by progressive neuropathological changes, which then become clinically detectable as cognitive impairment or dementia. The 'life-long' view of dementia stresses the importance of risk factors in midlife [31]. One of the problems with examining risk factors in middle age is the lack of standard criteria to judge poor cognitive performance and to assign its clinical significance. Recent attempts to identify poor performance as being in the worst quintile [32] provide appealing solutions to the problem. In addition to the results reported here, we also examined this association using linear regression; the results were no different. Our findings on individuals aged 55 and 61 years at the 2 phases of data collection suggest that low HRV is not a major risk factor at this point in life.

Previous studies have been on individuals with Alzheimer's disease and vascular dementia, making it diffi- 
Table 5. Cross-sectional associations between HRV (1 SD decrease) and cognitive functioning (odds of lowest quintile) among participants with coronary heart disease

\begin{tabular}{|c|c|c|c|c|c|c|c|c|c|c|}
\hline & \multicolumn{2}{|c|}{ Memory } & \multicolumn{2}{|c|}{ AH4-I } & \multicolumn{2}{|c|}{ Mill Hill } & \multicolumn{2}{|c|}{ Phonemic } & \multicolumn{2}{|c|}{ Semantic } \\
\hline & OR & $95 \%$ CI & OR & $95 \%$ CI & OR & $95 \%$ CI & OR & $95 \% \mathrm{CI}$ & OR & $95 \%$ CI \\
\hline \multicolumn{11}{|c|}{ HRV measures - phase $5^{1}$} \\
\hline SDNN & 1.23 & $0.85-1.77$ & 1.56 & $1.10-2.23$ & 1.13 & $0.79-1.62$ & 1.10 & $0.78-1.54$ & 1.27 & $0.91-1.78$ \\
\hline $\mathrm{HF}$ & 1.26 & $0.88-1.80$ & 1.27 & $0.92-1.76$ & 0.97 & $0.69-1.36$ & 1.16 & $0.84-1.60$ & 1.07 & $0.78-1.48$ \\
\hline LF & 1.55 & $1.05-2.29$ & 1.59 & $1.09-2.31$ & 1.26 & $0.87-1.83$ & 1.09 & $0.77-1.55$ & 1.31 & $0.92-1.85$ \\
\hline \multicolumn{11}{|c|}{ HRV measures - phase $7^{2}$} \\
\hline SDNN & 0.94 & $0.74-1.19$ & 1.05 & $0.82-1.34$ & 0.94 & $0.73-1.20$ & 1.12 & $0.86-1.45$ & 1.26 & $0.97-1.64$ \\
\hline $\mathrm{HF}$ & 1.01 & $0.79-1.29$ & 0.94 & $0.73-1.20$ & 0.91 & $0.71-1.17$ & 1.09 & $0.83-1.42$ & 1.11 & $0.86-1.43$ \\
\hline LF & 0.87 & $0.68-1.12$ & 1.04 & $0.81-1.34$ & 0.95 & $0.74-1.23$ & 1.14 & $0.87-1.49$ & 1.19 & $0.91-1.54$ \\
\hline
\end{tabular}

OR are adjusted for age, sex and highest educational attainment.

${ }^{1} \mathrm{n}=211$ (115 men, 56 women).

${ }^{2} \mathrm{n}=353$ (272 men, 81 women).

Table 6. Prospective association between HRV at phase 5 (1 SD decrease) and cognitive functioning at phase 7 (odds of lowest quintile) among participants with coronary heart disease

\begin{tabular}{|c|c|c|c|c|c|c|c|c|c|c|}
\hline & \multicolumn{2}{|c|}{ Memory } & \multicolumn{2}{|c|}{ AH4-I } & \multicolumn{2}{|c|}{ Mill Hill } & \multicolumn{2}{|c|}{ Phonemic } & \multicolumn{2}{|c|}{ Semantic } \\
\hline & OR & $95 \% \mathrm{CI}$ & OR & $95 \% \mathrm{CI}$ & OR & $95 \% \mathrm{CI}$ & OR & $95 \%$ CI & OR & $95 \% \mathrm{CI}$ \\
\hline \multicolumn{11}{|c|}{ HRV measures } \\
\hline SDNN & 0.84 & $0.58-1.23$ & 1.25 & $0.84-1.86$ & 1.06 & $0.68-1.66$ & 1.04 & $0.72-1.50$ & 0.97 & $0.67-1.41$ \\
\hline $\mathrm{HF}$ & 0.83 & $0.58-1.18$ & 1.01 & $0.69-1.48$ & 0.99 & $0.64-1.52$ & 1.00 & $0.70-1.43$ & 0.95 & $0.66-1.36$ \\
\hline $\mathrm{LF}$ & 0.98 & $0.66-1.46$ & 1.45 & $0.95-2.20$ & 1.27 & $0.81-1.99$ & 1.11 & $0.75-1.63$ & 1.18 & $0.79-1.75$ \\
\hline
\end{tabular}

Total number of subjects $=181$ (132 men, 49 women). OR are adjusted for age, sex and highest educational attainment and the time interval between phases 5 and 7 .

cult to separate cause and effect. Alzheimer's disease patients have decreased parasympathetic tone, which can cause reduced HRV [24]. Allan et al. [33] found no difference in HRV measures between those with Alzheimer's disease or dementia and control patients. In contrast, Murakami et al. [34] reported that LF and the LF/HF ratio were significantly lower in a group with dementia than in a normal control group, among individuals aged 75 years and older. We used 5 tests in order to examine several cognitive dimensions; low HRV was not associated consistently with any test. The cross-sectional and longitudinal analysis showed some association, but not with the same cognitive domain, leading to the conclusion that there is no real association between HRV and cognition in our data. Given these mixed findings, further research is clearly needed.
One possible pathway that may link HRV to cognitive function is through increased blood pressure [24], but we found no evidence of an association among a group of our participants with hypertension. HRV is linked to heart disease, and there is some evidence to suggest that heart disease is associated with impaired cognition $[13,14]$. It is plausible, therefore, that associations between reduced cardiac autonomic function and impaired cognition may only be present among those with prevalent coronary heart disease. In a sub-group of our participants with angina or myocardial infarction, there was a suggestion of a stronger relationship between HRV and cognitive function (in particular memory and AH4-I). This warrants further investigation in a larger group of people with coronary disease. 
There are a number of potential limitations to this study. First, Whitehall II is a study on individuals in stable civil service white-collar jobs at baseline, and thus does not represent the general population, particularly the lowest end of the socio-economic spectrum, the unemployed or those in insecure jobs. Thus, further research is needed to determine the generalizability of our findings. Second, data here are drawn from the 5th and 7 th phases of the study, implying both survival and selection effects. Therefore, it is possible that the association between HRV and cognition is underestimated in our sample. Since the Whitehall II study collected only 5-min short-term electrocardiograms, we were not able to investigate recently proposed advanced methods for HRV assessment that appear to be capable of differentiating sympathetic and vagal influences in long-term electrocardiograms [35]. It is possible that more sophisticated measurements of heart rate variability may have provided different results. Finally, the Whitehall II cognitive test battery does not assess executive functions in detail. It is also possible that additional neuropsychological test- ing would have shown effects not evident in the tests included in our analysis.

In conclusion, our results show low HRV is not consistently associated with aspects of poor cognitive function in this middle-aged sample of men and women. Ongoing follow-ups and further testing as the study participants grow older will verify the potential role of HRV measures in predicting the degeneration of cognitive function at older ages.

\section{Acknowledgements}

The Whitehall II study has been supported by grants from the British Medical Research Council; British Economic and Social Research Council; British Heart Foundation; UK Health and Safety Executive; UK Department of Health; National Heart Lung and Blood Institute (HL36310), US, National Institutes of Health; National Institute on Aging (AG13196), US, National Institutes of Health; Agency for Health Care Policy Research (HS06516); The John D and Catherine T MacArthur Foundation Research Networks on Successful Midlife Development and Socio-Economic Status and Health.

\section{References}

$\checkmark 1$ Morris JC, Storandt M, Miller JP, McKeel DW, Price JL, Rubin EH, et al: Mild cognitive impairment represents early-stage Alzheimer disease. Arch Neurol 2001;58:397-405.

2 Chertkow H: Mild cognitive impairment. Curr Opin Neurol 2002;15:401-407.

- 3 Fried LP, Kronmal RA, Newman AB, et al: Risk factors for 5 -year mortality in older adults. JAMA 1998;279:585-592.

-4 Bassuk SS, Wyppij D, Berkman LF: Cognitive impairment and mortality in the community-dwelling elderly. Am J Epidemiol 2000;151:676-688.

$\checkmark 5$ Kuh D, Richards M, Hardy R, et al: Childhood cognitive ability and deaths up until middle age: a post-war birth cohort study. Int J Epidemiol 2004;33:408-413.

6 Graham JE, Rockwood K, Beattie BL, et al: Prevalence and severity of cognitive impairment with and without dementia in an elderly population. Lancet 1997;349:1793-1796.

7 Holland CA, Rabbitt P: The course and causes of cognitive change with advancing age. Rev Clin Gerontol 1991;1:81-96.

-8 Singh-Manoux A, Britton A, Marmot M: Vascular disease and cognitive function: evidence from the Whitehall II study. J Am Geriatr Soc 2003;51:1445-1450.
-9 Singh-Manoux A, Britton A, Kivimaki M, Gueguen A, Halcox J, Marmot M: Socioeconomic status moderates the association between carotid intima-media thickness and cognition in midlife: evidence from the Whitehall II Study. Atherosclerosis 2008; 197:541-548.

10 Singh-Manoux A, Marmot M: High blood pressure was associated with cognitive function in middle-age in the Whitehall II study. J Clin Epidemiol 2005;58:1308-1315.

11 Britton A, Singh-Manoux A, Marmot M: Alcohol consumption and cognitive function in the Whitehall II study. Am J Epidemiol 2004;160:240-247.

12 Singh-Manoux A, Hillsdon M, Brunner E, Marmot M: Effects of physical activity on cognitive functioning in middle-age: evidence from the Whitehall II prospective cohort study. Am J Public Health 2005;95: 2252-2258.

13 Aronson MK, Ooi WL, Morgenstern $\mathrm{H}$, et al: Women, myocardial infarction, and dementia in the very old. Neurology 1990;40:11021106.

14 Muller M, Grobbee DE, Aleman A, et al: Cardiovascular disease and cognitive performance in middle-aged and elderly men. Atherosclerosis 2007;190:143-149.

15 Liao D, Cai J, Barnes RW, et al: Association of cardiac autonomic function and the development of hypertension: the ARIC study. Am J Hypertens 1996;9:1147-1156.
6 Thayer JF, Lane RD: The role of vagal function in the risk for cardiovascular disease and mortality. Biol Psychobiol 2007;74:224242.

17 Britton A, Shipley M, Malik M, Hnatkova K, Hemingway $\mathrm{H}$, Marmot M: Changes in heart rate and heart rate variability over time in middle-aged men and women in the general population (from the Whitehall II Cohort Study). Am J Cardiol 2007; 100:524-527.

- 18 Liao D, Cai J, Rosamond WD, Barnes RW, Hutchinson RG, Whitsel EA, et al: Cardiac autonomic function and incident coronary heart disease: a population-based case-cohort study. The ARIC Study: Atherosclerosis Risk in Communities Study. Am J Epidemiol 1997;145:696-706.

19 Kleiger RE, Miller JP, Bigger JT Jr, Moss AJ: Decreased heart rate variability and its association with increased mortality after acute myocardial infarction. Am J Cardiol 1987:59:256-262.

20 Farrell TG, Bashir Y, Cripps T, Malik M, Poloniecki J, Bennett ED, et al: Risk stratification for arrhythmic events in postinfarction patients based on heart rate variability, ambulatory electrocardiographic variables and the signal-averaged electrocardiogram. J Am Coll Cardiol 1991;18:687-697. 
21 Bigger JT Jr, Fleiss JL, Steinman RC, Rolnitzky LM, Kleiger RE, Rottman JN, et al: Frequency domain measures of heart period variability and mortality after myocardial infarction. Circulation 1992;85:164-171.

-22 Moroney JT, Tang MX, Berglund L, Small S, Merchant C, Bell K, et al: Low-density lipoprotein cholesterol and the risk of dementia with stroke. JAMA 1999;282:254-260.

-23 Karlamangla AS, Singer BH, Chodosh J, McEwen BS, Seeman TE: Urinary cortisol excretion as a predictor of incident cognitive impairment. Neurobiol Aging 2005;26 (suppl 1):80-84.

24 Kim DH, Lipsitz LA, Ferrucci L, Varadhan R, Guralnik JM, Carlson MC, et al: Association between reduced heart rate variability and cognitive impairment in older disable women in the community: Women's Health and Aging Study I. J Am Geratr Soc 2006; 554:1751-1757.
5 Zulli R, Nicosia F, Borroni B, Agostil C, Prometti P, Donati P, et al: QT dispersion and heart rate variability abnormalities in Alzheimer's disease and in mild cognitive impairment. J Am Geriatr Soc 2005;53: 2135-2139.

26 Marmot MG, Davey Smith G, Stansfeld S, Patel C, North F, Head J, et al: Health inequalities among British civil servants: the Whitehall II study. Lancet 1991;337:13871393

27 Marmot M, Brunner E: Cohort profile: The Whitehall II Study. Int J Epidemiol 2005;34: 251-256.

28 Heim AW: AH4 group test of general intelligence ASE. Windsor, NFER-Nelson, 1970.

29 Raven JC: Guide to Using the Mill Hill Vocabulary Scale with Progressive Matrices. London, HK Lewis, 1965.

30 Borkowski JG, Benton AL, Spreen O: Word fluency and brain damage. Neuropsychologica 1967;5:135-140.

-31 Kivipelto M, Ngandu T, Laatikainen T, Winblad B, Soininen H, Tuomilehto J, et al: Risk score for the prediction of dementia risk in 20 years among middle aged people: a longitudinal, population-based study. Lancet Neurol 2006;5:735-741.
32 Anstey KJ, Luszcz MA, Giles LC, Andrews GR: Demographic, health, cognitive, and sensory variables as predictors of mortality in very old adults. Psychol Aging 2001;16: 3-11.

33 Allan LM, Kerr SR, Ballard CG, Allen J, Murray A, McLaren AT, Kenny RA: Autonomic function assessed by heart rate variability is normal in Alzheimer's disease and vascular dementia. Dement Geriatr Cogn Disord 2005;19:140-144.

34 Murakami S, Yamanaka T, Kubo Y, Wada T, Yano S, Nighimura Y, et al: Heart rate variability analysis and neurobehavioral function in community-dwelling older people aged 75 or older. Nippon Ronen Igakkai Zasshi 2002;39:520-526.

35 Bauer A, Kantelhardt JW, Barthel P, Schneider R, Mäkikallio T, Ulm K, Hnatkova $\mathrm{K}$, Schömig A, Huikuri H, Bunde A, Malik M, Schmidt G: Deceleration capacity of heart rate as a predictor of mortality after myocardial infarction: cohort study. Lancet 2006; 367:1674-1681. 